\title{
Analisa Pemanfaatan Google Custom Search Pada Website Yufid.com dengan Metode Kualitatif Deskriptif
}

\author{
Khozin Yuliana*1 ${ }^{*}$, Arief Saptono ${ }^{2}$, Nadya Cahyaningsih ${ }^{3}$ \\ ${ }^{1}$ Program Studi Komputerisasi Akuntansi Universitas Raharja, ${ }^{2,3}$ Program Studi Sistem \\ Informasi Universitas Raharja \\ E-mail: *1khozin@ raharja.info, ${ }^{2}$ arief.saptono@ raharja.info, \\ ${ }^{3}$ nadya.cahyaningsih@ raharja.info
}

\begin{abstract}
Abstrak
Perkembangan teknologi yang sangatlah pesat dijaman sekarang, membuat banyak masyarakat menjadi banyak terkena banyakanya penyebaran berita berita hoax yang biasanya membuat judul yang profokatif. Hal ini juga menjadikan Hadits yakni sebagai salah satu pegangan umat muslim dalam beragama juga ikut di palsukan oleh orang orang yang tidak bertanggung jawab, dan membuat banyak orang yang masih awam bisa tertipu dengan adanya hoax ini. Dalam jurnal ini, akan di jelaskan tentang adanya sebuah situs dengan menggunakan kecanggihan teknologinya membuat suatu mesin pencarian islam yang isinya dapat dipertanggung jawabkan. Dengan menggunakan metode Kualitatif Deskriptif kita akan melihat Google Custom Search yang dimanfaatkan oleh situs Yufid.com dalam membuat suatu terobosan yang bermanfaat bagi orang banyak. Dengan ini membuktikan bahwa Google Custom Search dapat memiliki fungsi yang sangat baik untuk menyortir berbagai macam persoalan yang paling beresiko yaitu Hadits Palsu.
\end{abstract}

Kata Kunci-Google Custom Search, Hadits Shahih, Hadits Palsu,

\begin{abstract}
The technology nowadays is really improved so much in our era. Its making people being dragged by too much false news that really has a provocative title. This is also making a hadith that is a guide to Muslims being one of the objects that are forged by some people. It's also making many people who don't have a strong background to study Islam being dragged into false hadith. In this journal, we will explain about a site with that advanced technology they are making a search machine and any answer on that site is responsible. With the use of google custom search, yufid.com site making a breakthrough that many people will get the benefit. This is proving that Google Custom Search can have a powerfull use to sort something so risky like Hadits Mawdu'
\end{abstract}

Keywords-Google Custom Search, Shahih Hadith, Hadits Mawdu',.

\section{PENDAHULUAN}

Berkembanganya Teknologi di jaman sekarang membuat banyak sekali perubahan dalam kehidupan manusia. Baik perubahan yang baik maupun yang buruk. Ditambah maraknya social media yang dimana jika kita tidak dengan bijak menggunakannya maka kita akan mendapatkan hasil yang negative. Beberapa social media besar seperti Facebook menjadi sasaran empuk bagi orang orang yang menyebarkan hoax ke tengah masyarakat. Begitu pula dengan Instagram maupun whatsapp yang juga tak luput dari kabar kabar hoax. Ditambah lagi, 
adanya website website pembuat berita palsu dan akhirnya membuat masyarakat yang awam percaya.

Topik yang tak luput dari di palsukan adalah Hadits. Pada zaman kita sekarang, telah banyak beredar beberapa hadits palsu yang dilariskan oleh para penceramah di mimbar, di sekolah, dan di berbagai perkumpulan disebabkan kurangnya pengetahuan manusia tentang ilmu hadits dan sedikitnya orang yang ahli di bidang hadits [1]

Sebagai seorang muslim, mereka diwajibkan untuk selalu berpegang kepada kitab suci mereka yaitu Al-Quran dan Hadits. Secara etimologi Hadits adalah sesuatu yang baru, dan merupakan bentuk jamak dari ahadits. Secara terminology Hadits adalah apa saja yang dinisbatkan kepada Nabi Muhammad صلى الله عليه وسلم baik berupa perkataan, perbuatan, taqrir (sikap diam setuju), dan sifat [2]

Nampaknya jika ada yang membuat hadist palsu, dia sudah kehilangan rasa malunya, redaksi sama, dan hanya menggunakan metode copy paste. Namun ini bukan sesuatu yang mengherankan, seperti yang diriwayatkan oleh al-Uqaily dari Hammad bin Zaid, bahwa orangorang zindiq (munafiq) yang pernah membuat hadits palsu sebanyak 14.000 hadits! Dan tiga orang yang terkenal sebagai pemalsu hadits pernah membuat hadits palsu lebih dari 4000 hadits! [3]

Dari penjelasan diatas, sangatlah berbahaya jika Hadits yang dipakai umat muslim untuk berpegang teguh ternyata ada yang dipalsukan. Hal buruk yang akan terjadi adalah, umat islam bisa saja beribadah dengan cara yang tidak benar, yang tidak pernah dicontohkan oleh Nabi Muhammad صلى الله عليه وسلم sekalipun karena ketidaktahuan dan kurangnya ilmu hadits. Dan dalam agama islam, jika kita beribadah dengan cara yang tidak ada tuntunannya atau tidak memiliki dalil yang kuat, maka ibadahnya tersebut tertolak walaupun terlihat baik. Seperti kata Rasulullah Barangsiapa yang mengada-adakan suatu perkara di dalam urusan [agama] kami ini yang bukan berasal darinya, maka ia pasti tertolak." (HR. Bukhari dan Muslim)

Salah satu Upaya dari banyak orang yang berusaha memurnikan hadits adalah mereka membuat suatu website dan didalamnya mereka bekerja sama dengan Google Custom Search sehingga kedepannya diharapkan, umat muslim bisa tau mana hadits yang shahih dan mana yang palsu.

\section{METODE PENELITIAN}

Penelitian ini menggunakan metode penelitian kualitatif deskriptif. Menurut Maman $(2002 ; 3)$ penelitian deskriptif berusaha menggambarkan suatu gejala sosial. Dengan kata lain penelitian ini bertujuan untuk menggambarkan sifat sesuatu yang tengah berlangsung pada saat studi. Metode kualitatif ini memberikan informasi yang mutakhir sehingga bermanfaat bagi perkembangan ilmu pengetahuan serta lebih banyak dapat diterapkan pada berbagai masalah (Husein Umar, 1999:81).

Untuk membuat Jurnal ini saya menggunakan Metode deskriptif, Metode ini memiliki sebuah tujuan untuk bisa mengumpulkan data secara detail, mendalam dan juga actual. Di dalam sebuah penelitian biasanya akan di jelaskan mengenai gejala-gejala yang sudah ada misalnya tentang masalah serta meneliti kondisi yang tetap berlaku. Penelitian ini juga menjadikan perbandingan tentang apa yang bisa di lakukan untuk menentukan sebuah solusi dalam menghadapi sebuah permasalahan.

Lokasi Penelitian adalah website Yufid.com itu sendiri. Sedangkan untuk pengumpulan datanya saya melakukan Observasi, Menurut Arikunto (2006:124) observasi adalah mengumpulkan data atau keterangan yang harus dijalankan dengan melakukan usaha-usaha pengamatan secara langsung ke tempat yang akan diselidiki. Dengan mengobservasi lingkungan di sekitar saat ada Pengajian dimana banyak yang menggunakan Yufid.com ini sebagai media mereka untuk mencari Hadits yang sudah disebutkan oleh Ustadz saat materi dan Kelas Tauhid Online HSI AbdullahRoy (Yang saat ini peserta Angkatan 201 Wanita berjumlah kurang lebih 
23 ribu orang) yang menyarankan peserta jika kesulitan mencari hadits yang telah disebutkan di materi untuk mencarinya lewat Yufid.com yang kebetulan saya merupakan admin di Angkatan 201 ini dan juga dari website Yufid.com itu sendiri.

\section{HASIL DAN PEMBAHASAN}

Apa perbedaan dari hadits Shahih dan Hadits Palsu?. Hadits Shahih menurut etimologi, As-Shahih lawn kata dari saqim (sakit). Kata ini digunakan secara hakikat untuk badan dan secara majaz untuk hadits dan yang lainnya. Sedangkan secara terminology, As-Shahih adalah hadits yang bersambung sanadnya, diriwayatkan oleh orang-orang yang adil serta kuat ingatannya (dhabith), dari yang semisalnya hingga akhir (sanad), tanpa ada penyimpangan (syudzudz) dan cacat ('illah). Syarat yang harus ada dalam suatu hadits agar dinilai menjadi shahih, yaitu :

a. Sanadnya bersambung, yang berarti setiap rawi dalam hadits tersebut benar-benar telah mengambil secara langsung dari gurunya, hal seperti ini diharuskan mulai dari awal sanad hingga akhirnya.

b. Sifat adil seorang rawi, Maksid dari adil disini ialah setiap rawi hadits harus memiliki difat sebagai muslim, balig, berakal, tidak fasik, dan tidak tercela perilakunya

c. Sifat dhabith seorang rawi, yaitu setiap rawi hadits tersebut harus benar-benar sempurna hafalannya, baik hafalan tanp menggunakan kitab maupun menggunakan kitab ( yang terjaga dari pemalsuan)

d. Tidak Syadz, yaitu benar-benar tidak ada penyimpangan dalam hadits tersebut, Syadz adalah rawi yang Tsiqah menyelisihi riwayat rawi yang lebih tsiqah darinya.

e. Tidak ada Cacat (iilah), yaitu hadits tersebut benar-benar tidak terdapat kecacatan didalamnya. Cacat (dalam hadits) adalah sebab-sebab perusak hadits yang bersifat samar dan tersembunyi, walaupun hadits tersebut terlihat selamat dari sebab-sebab tersebut.

Sedangkan Hadits Palsu (Maudhu') dinamakan seperti itu jika sebab cacatnya rawi adalah sengaja berdusta atas nama Rasulullah صلى الله عليه وسلم. Secara Etimologi, Al-Maudhu' adalah ism maf'ul dari wadha'a yang berarti meletakkan, dinamakan demikian dikarenakan kedudukannya yang buruk. Secara terminology, Al-Maudhu' adalah kedustaan yang direkayasa dan dibuat-buat serta dinisbatkan kepada Rasulullah صلى الله عليه وسلم . Derajat hadits AlMaudhu' adalah seburuk-buruknya hadits dhaif dan sejelek-jeleknya. Para ulama sepakat, bahwasannya tidak boleh bagi siapapun yang mengetahui kepalsuan hadits tersebut untuk meriwayatkannya, kecuali jika telah dijelaskan kepalsuanya.

صلى الله عليه Imam Adz-Dzahabi memasukan dosa berdusta atas nama Nabi Muhammad ke urutan nomor 9. Adapun jika dengan sengaja menafsirkan firman Allah dengan sesuatu yang tidak dimaksudkan oleh Allah karena mengikuti hawa nafsu atau untuk memuaskan kepentingan seseorang atau untuk yang lainnya, maka ia termasuk orang-orang yang berdusta dengan mengatasnamakan Allah. Demikian juga halnya dengan orang-orang yang berdusta atas صلى الله عليه Misalnya, dengan mengatakan bahwa Rasulullah صلى الله عليه وسلم telah bersabda begini. Padahal beliau tidak pernah mengatakannya. Namun, orang tersebut hanya ingin berdusta dengan mengatasnamakan Rasulullah صلى الله عليه وسلم . Demikian juga halnya jika menfasirkan Hadits Rasulullah صلى الله عليه وسلم dengan sesuatu yang tidak sesuai dengan maknanya. Maka ia telah berdusta atas nama Rasulullah صلى الله عليه وسلم . Karena sesungguhnya Rasulullah صلى الله عليه وسلم bersabda, "Barangsiapa, yang berdusta atas namaku dengan sengaja, maka bersiaplah untuk mengambil tempat duduk di dalam neraka."

Maknanya bahwa siapa saja yang berdusta mengatasnamakan Rasulullah صلى الله عليه dengan sengaja, maka sesungguhnya dia telah mengambil tempat duduknya didalam neraka dan (kelak) ia akan menempatinya. Inilah dua macam dusta yang termasuk dusta yang paling jahat. Yaitu berdusta atas nama Allah dan berdusta Atas nama Rasulullah [4]. صلى الله عليه وسلم

Perlu dicermati juga bahwa hadits-hadits lemah dan palsu ini memiliki dampak negatif dan kerusakan yang lumayan banyak pada masyarakat, baik berkaitan dengan aqidah mereka, 
cara ibadah mereka, dan sebagainya [5]. Maka di antara salah satu faktor penting tersebarnya syirik, bid'ah, pertikaian, dan kerusakan moral adalah tersebarnya hadits-hadits palsu yang dialamatkan kepada Nabi صلى الله عليه وسلم. Agar lebih jelas, kita akan menampilkan sebuah contoh berikut, "Apabila kalian ditimpa kesulitan maka mintalah pertolongan kepada ahli kubur."

Hadits yang dusta dengan kesepakatan ulama ini [6] sangat berdampak negatif bagi aqidah umat. Syaikh Abdul Aziz bin Baz berkata, "Hadits ini mengajak kepada perbuatan syirik kepada Allah, sebab meminta pertolongan kepada ahli kubur termasuk syirik yang amat nyata dengan kesepakatan ahli ilmu dan iman. Maka nyatalah bahwa hadits ini hanyalah buatan para pengagum kubur. Semoga Allah membalas orang yang membuatnya." [7]

Dengan majunya perkembangan teknologi dijaman sekarang, bukan hal yang sulit untuk setiap oramg berbuat kerusakan dengan apa yang di postingnya, diketiknya, atau dikomennya. Apalagi, ternyata penyebaran hoax ternyata mempunyai jaringan tersendiri. Secara umum ada dua kelompok besar situs penyebar kabar pelintiran. Pertama, akun pribadi dan situs yang terafiliasi ke partai politik yang telah diblokir Kementerian Komunikasi dan Informatika. Data World Traffic menunjukkan, situs tersebut sebelum diblokir dikunjungi 300 ribu orang per hari. Situs ini menangguk iklan US\$ 100 per hari, US\$ 36.500 setahun atau setara dengan Rp 485 juta. Kelompok kedua adalah situs yang memang berusaha mencari untung. Mereka telah diblokir pemerintah berdasarkan Peraturan Menteri Kominfo Nomor 19 Tahun 2014 tentang Internet Sehat. Situs semacam ini gemar meramu fakta dengan fiksi, ditambah judul dan opini yang provokatif. Riset Komunitas Masyarakat AntiHoax menunjukkan situs sejenis ini memanen iklan Rp 600-700 juta setahun.[8]

Dengan begitu terstrukturnya pembuatan hoax di Indonesia, masyarakat bisa dengan mudah menemukan berita berita hoax yang Bahasa maupun isinya sudah terstruktur untuk mengelabuhi banyak orang. Fenomena ini diperparah dengan adanya fakta yang menyedihkan bahwa kondisi literasi di Indonesia sangat menyedihkan, Literasi di Indonesia masuk urutan ke 64 dari 65 negara. Tingkat membaca siswa di Indonesia juga termasuk sangat rendah dibandingan dengan negara-negara lain di dunia, yaitu masuk dalam urutan ke 57 dari 67 negara (PISA, 2010) sehingga jika dihitung indeks minat membaca di Indonesia adalah 0,001 yang maksudnya adalah setiap 1.000 penduduk hanya 1 yang membaca. Dan jangan lupakan fakta bahwa Indonesia juga masih dalam posisi yang tidak aman penduduk buta aksara dengan presentase 65,5 persen (UNESCO, 2012)

Penyebaran hoax di media sosial Indonesia memasuki fase yang cukup mengkhawatirkan, karena berdampak serius terhadap kehidupan sosial warga bangsa. Pertemanan putus, keluarga tidak harmonis, bahkan konflik horizontal sempat terjadi ketika ada sebagian warga yang termakan oleh berita hoax.[9]

Berdasarkan hasil Survey dari KOMINFO pada tahun 2017 yang lalu, Hasil survei Kominfo pada tahun 2017 menunjukkan bahwa lebih dari setengah masyarakat Indonesia sudah memiliki telepon pintar atau smartphone yakni sekitar 66.3\% individu memiliki Smartphone yang dimana di daerah Urban sekitar 83,04\% dari penduduknya mempunyai Smartphone dan sekitar 50,39\% di daerah rural yang memiliki smartphone. Penggunaan Smartphone sehari-hari penduduk Indonesia adalah sekitar 1-3 jam sehari dengan rentang umur 20-29 tahun menjadi yang paling banyak menggunakan Smartphone dan semakin tinggi tingkat pendidikannya maka semakin meningkat juga penggunaan Smartphonennya. Sedangkan untuk penggunaan internet sekitar $45 \%$ penduduk Indonesia menggunakan internet.yang aktivitas yang paling tinggi di gunakan untuk Internet Communication dan Web Browsing. Penggunaan social media oleh penduduk Indonesia pada tahun 2017 adalah 92,82\% yang menunjukan hampir semua yang menggunakan internet menggunakan Sosial media.dan social media seperti Facebook adalah social media yang sering di akses oleh penduduk rural, dan di daeran urban Pinterest adalah yang paling sering di gunakan. Dan umur penggunanya yang paling banyak adalah 20-29 tahun dengan durasi 1-3 jam perharinya. Untuk aplikasi social messaging seperti Google Hangout, Facebook messenger, Whatsapp, Line, dan telegram memiliki sekitar $84,76 \%$ pengguna yang didominasi pengguna perempuan dan umur rata-rata yang menggunakannya sekiat 20-29 tahun. 
Dari hasil diatas kita sudah melihat masifnya penggunaan internet dan social media yang digunakan oleh penduduk di Indonesia. Itulah kenapa kabar hoax sangat berkembang dengan cepat. Sebenarnya apakah yang disebut dengan Hoaks? Berdasarkan kamus besar Bahasa Indonesia (KBBI), hoaks didefinisikan sebagai berita bohong sementara MerriamWebster mendefinisikan hoaks sebagai suatu tindakan yang menbuat sesuatu yang salah atau tidak masuk akal dapat dipercaya atau diterima sebagai sesuatu yang benar. Atau dapat disimpulkan bahwa hoaks adalah suatu berita/informasi yang tidak benar yang dibuat seolaholeah benar sehingga dipercaya oleh orang lain. Kata hoaks sendiri diduga pertama kali muali popular digunakan pada pertengahan hingga akhir abad ke-18, berasal dari frasa hocus pocus yang menggunakan istilah dalam dunia sulap menyulap.

Pada tahun 2017, Masyarakat Telematika Indonesia (MASTEL) melakukan survey terkait hoaks di Indonesia. Dari hasil survey tersebut dapat dilihat bahwa saluran penyebaran hoaks paling besar berasal dari Media Sosial serta Aplikasi Chatting, jauh lebih tinggi dibandingkan media penyebaran lainnya seperti radio, media cetak, dan televisi. Hal ini memperlihatkan bahwa peran internet dalam penyebaran hoaks ini sangatlah besar. Survey tersebut juga engungkapkan bahwa intensitas penerimaan hoaks dari para responden paling tinggi adalah setiap hari (44,3\% dari responden). Hal ini merupakan sesuatu yang cukup mengkhawatirkan karena dapat dikatakan bahwa hoaks di Indonesia tersebar cukup masif.[10]

Cara untuk mengenali Hoaks perlu terus di edukasi untuk bisa mengidentifikasi secara sadar perihal berita sesat alias "hoax" yang kini masih tersebar luas di dunia maya dengan ciriciri sebagai berikut :[11]

a. Berasal dari situs yang tidak dapat dipercayai.

- Belum memiliki tim redaksi (jika itu situs berita).

- Keterangan tentang siapa penulisnya tidak jelas (Halaman ABOUT - Untuk situs Blog)

- Tidak memiliki keterangan siapa pemiliknya. dihubungi.

- Nomor telepon dan email pemilik tidak tidak tercantum. Sekalipun ada tapi tidak bisa

- Domain tidak jelas

b. Tidak ada tanggal kejadiannya.

c. Tempat kejadiannya tidak jelas.

d. Menekankan pada isu SARA/ syarat dengan isu SARA yang berlebihan.

e. Kebanyakan kontennya aneh dan dengan lugas juga tegas menyudutkan pihak tertentu. Saat anda memeriksa tulisan yang lainnya juga demikian: tidak bermutu dan merendahkan pihak tertentu secara berlebihan (lebay).

f. Beritanya tidak berimbang. Menyampaikan fakta dan pertimbangan yang berat sebelah.

g. Alur cerita dan kontennya tidak logis, langka dan aneh.

h. Bahasa dan tata kalimat yang digunakan agak rancu dan tidak berhubungan satu sama lain.

i. Menggunakan bahasa yang sangat emosional dan provokatif.

j. Menyarankan anda untuk mengklik, mengshare dan melike tulisannya dengan nada yang lebay. Misalnya:

- "Jika anda seorang muslim klik...."

- "Share tulisan ini agar keluarga anda tidak menjadi korbannya...."

- "Like \& share sebelum terlambat...."

- "Rugi kalau tidak diklik...."

- "Kesempatan anda satu-satunya disini...."

- dan lain sebagainya.

Google Custom Search sendiri adalah Produk dari Google Inc, yang dapat menyediakan Mesin pencari untuk website, blog, atau banyak website. Kita dapat mengkonfigurasi hasil pencarian kita dengan webpage maupun foto. Kita juga bisa melihat rangking untuk hasil pencarian tertinggi, menambahkan iklan kita sendiri dan merancang bagaimana tampilan untuk hasil pencarian. Kita juga bisa membuatnya menjadi ter monetize dengan cara 
menghubungkannya dengan akun Google AdSense. Kita dapat menyortir mana saja website yang akan muncul dalam hasil perncarian kita. Dan kita juga bisa bebas menghapusnya kapan saja jika memang tidak sesuai. Dan berikut ini Keuntungan penggunaan Google Custom Search

- It is powered by Google's search algorithm - which is the best search algorithm. Fitur ini menggunakan Algoritma Google Search yang mana merupakan Algoritma pencari terbaik

- Kita bisa mengkustomisasi tampilan dan juga hasil pencarian

- Kita bisa menggunakan fitur Autocomplete Custom Search Engine yang membuat query menjadi lebih cepat, juga

- Kita bisa menggunakan Google Custom Search untuk mencari ke beberapa website dalam satu waktu

- Sekarang CSE menyediakan beberapa layout yang bisa kita pilih

- Google akan terus memperhatikan Query pencarian dan akan memberikan Data Analitisnya kepada Admin[12]

Fitur yang paling penting dalam Kustomisasi CSE (Custom Search Engine) adalah berhubungan dengan 'Label'. Yaitu fitur yang dimasukan kedalam website yang berada di dalam Index Mesin Pencari untuk membantu user mendapatkan informasi yang terkait dan letaknya ada di paling atas [13] Di dalam tab utama dari bagian Setup, kita bisa mengganti nama dari mesin pencari itu sendiri, menentukan situs mana yang bisa masuk, mengaktifkan atau nonaktifkan pencarian gambar (di dalam Yufid.com opsi ini di aktifkan), memilih edisi CSE (Custom Search Engine) yang bisa digunakan untuk mensetting Bahasa di Interface mesin pencari, Lalu Menggunakan opsi 'Add' yang ada di bawah 'Site to Search', untuk memilih website yang dimasukan satu per satu dan di sortir berdasarkan labelnya.

Di dalam hal penyortiran ini Yufid.com memiliki persyaratan agar website bisa muncul di dalam mesin pencari yaitu, Website yang di terima hanya website yang bermuatan dakwah sesuai dengan Al Quran dan Sunnah yang shohih, dan tidak boleh mendaftarkan website untuk berjualan dan yang sejenisnya. Untuk masalah menyortir konten Yufid.com menyerahkannya kepada Ustadz Pembina di Yufid.com. Tentunya karena menggunakan google custom search hal ini bisa lebih mudah. Dan Yufid.com menyediakan 3 bahasa, yaitu Indonesia, Inggris, dan Arab dengan memuat 5 Label, Yaitu Semua Hasil, Video, Shahih, Sunnah, dan Palsu.

Hasilnya Hal ini membuat kita dapat membantu kita menyortir hasil pencarian yang lebih baik. Karena jika hanya mengandalkan Google search biasa, kita akan mendapatkan hasil yang bercampur dengan yang salah atau bahkan palsu. Ditambah ketidaktahuan kita tentang suatu hadits secara mendalam, kita bisa saja salah dalam mengambil artikel atau konten yang dihadirkan di pencarian umum. Yang dampaknya sudah di jelaskan di awal hasil pembahasan jurnal ini.
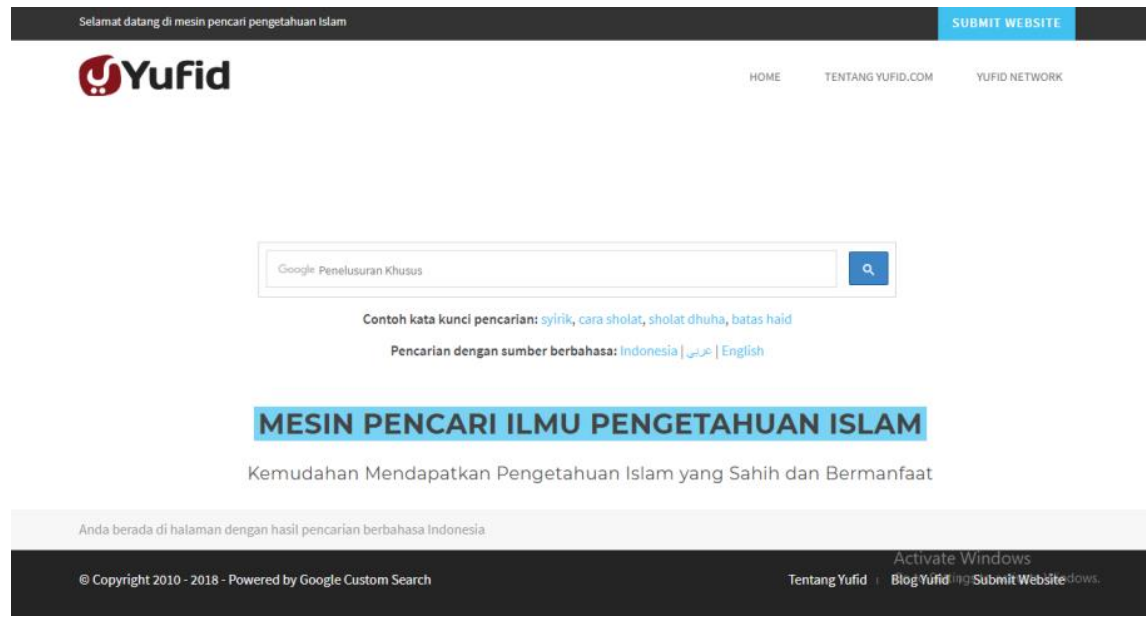

Gambar 1. Interface halaman Website Yufid.com 
Dunia maya adalah dunia tanpa tapal batas. Sekali kita mengetikkan satu kata kunci (misal: Islam) ke dalam mesin pencari (Google, misalnya), maka kita akan dibawa kepada ratusan ribu, jutaan, bahkan puluhan juta hasil pencarian. Itu semua adalah informasi yang berserakan di dunia maya, informasi yang shahih dan terpercaya bercampur dalam perangkap informasi-informasi yang menyesatkan,

Situs Yufid.com, mencoba memberikan satu solusi terhadap permasalahan yang saya gambarkan di atas. Berbagai website Islam dalam 3 bahasa (Indonesia, Inggris, dan Arab) mereka kumpulkan, mereka periksa dan mereka sortir satu per satu, kemudian mereka menyusunnya dan masukkan ke dalam teknologi mesin pencari Google yang sangat canggih.

Situs Yufid.com pada tahapan awal ini memberikan hasil pencarian khusus konten teks dalam 3 bahasa (Indonesia, Inggris, dan Arab). Kita bebas memilih menu bahasa untuk hasil pencarian sesuai dengan bahasa yang kita inginkan. Berikut di gambar dibawah di contohkan saat kita mencari Hadits di situs Yufid.com
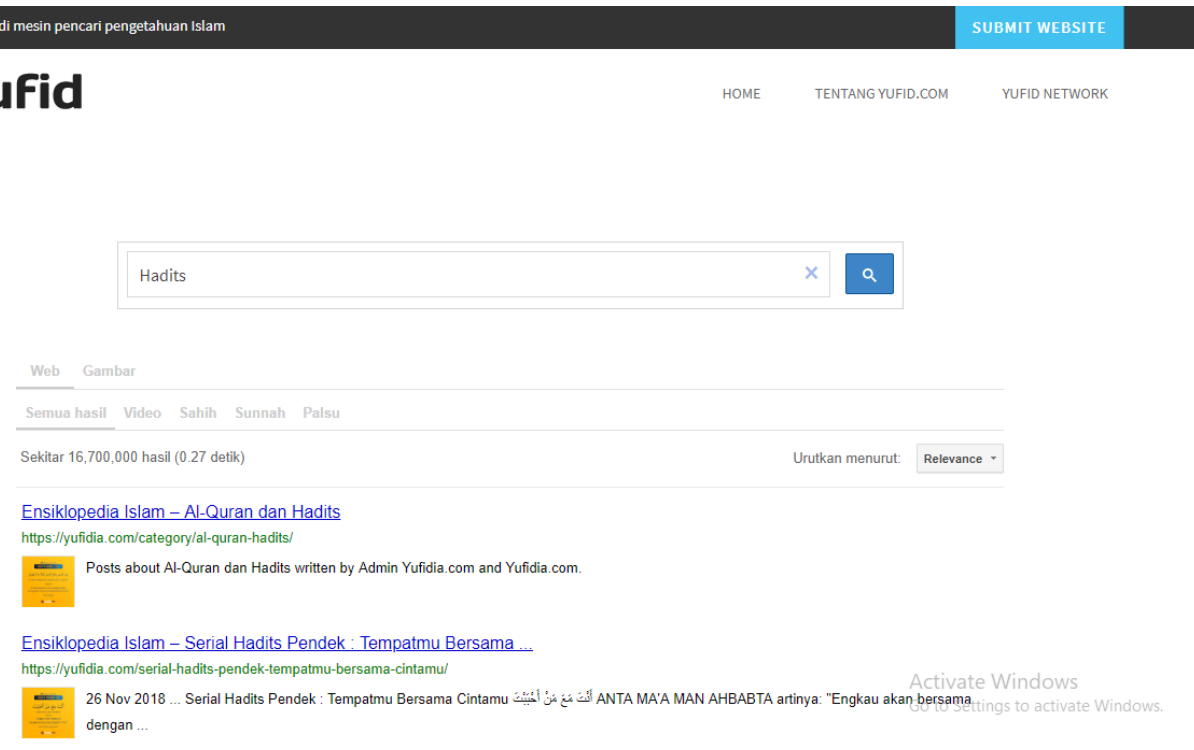

Gambar 2. Interface yang muncul untuk menampilan hasil pencarian

Dalam gambar diatas, menunjukkan hasil pencarian khusus yang telah disortir oleh situs tersebut sehingga kita akan mendapatkan hasil yang patut untuk di pertanggung jawabkan setiap artikelnya. Karena semua hasil pencariannya akan menunjukan menuju artikel tertentu yang sudah lengkap dengan dari buku mana, halaman berapa, dan hadits atau ayat yang keberapa, yang mana tidak akan kita temukan pada Hadits Hadits palsu yang tidak akan memiliki nomor hadits karena mereka sendiri tau mereka sedang membuat hadits palsu, dan tidak menyertakan nomor karena akan mudah terlacak jika hasil yang di cari tidak sesuai dengan berita bohong yang mereka buat. Mereka juga memiliki beberapa pilihan untuk hasil pencariannya, seperti jawaban dalam Video, Shahih, Sunnah, atau Palsu dan kita bebas memilih yang mana.

Dengan hadirnya situs mesin pencarian islam ini, membawa angin segar untuk umat yang sedang kebingungan dalam hal hal tertentu.yang membutuhkan tuntunan dalam agamanya. Dengan memasukan situs yang harus diteliti terlebih dahulu menyebabkan hasil web yang ditelusuri menjadi situs yang bisa di pertanggung jawabkan baik penulis yang membuat artikel tersebut maupun konten yang ditulis. Teknologi yang semakin berkembang seharusnya digunakan untuk hal-hal yang bermanfaat bagi manusia. Juga sebagai objek untuk membantu manusia. Dan penggunaan google custom search untuk membuat mesin pencarian islam ini merupakan salah satu penggunaan yang bermanfaat bagi orang banyak. 


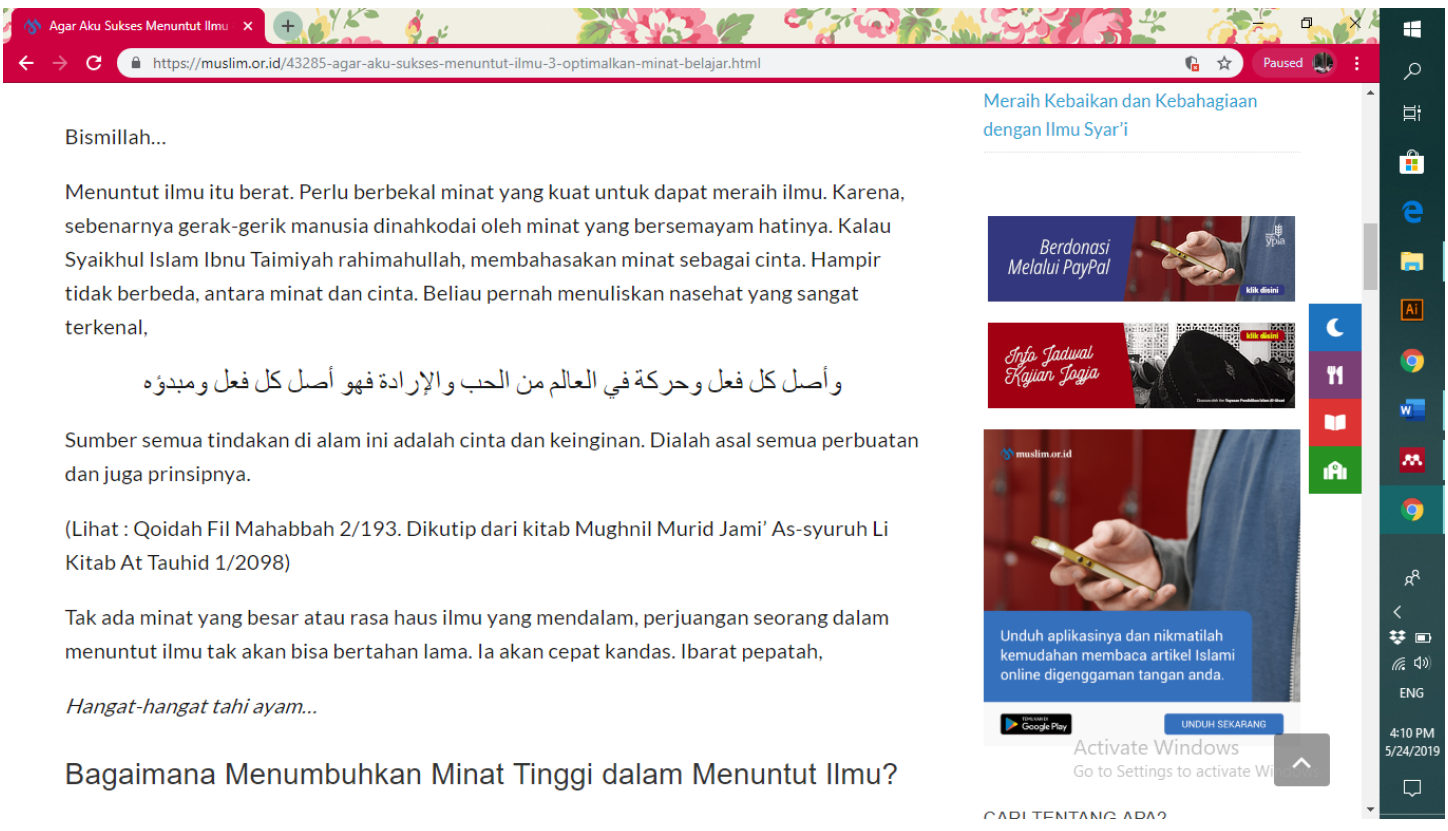

Gambar 1 Bukti bahwa setiap artikel yang ditampilkan juga memiliki catatan kaki

Tidak semua orang dapat memfokuskan dan mendalami ilmu agama ini. Dan tidak semua orang juga dapat menghadiri kajian kajian yang di gelar oleh majelis ta'lim ataupun masjid. Dengan adanya mesin pencarian ini setidaknya masyarakat dapat mengambil sumber sumber bacaan yang benar dan dapat di pertanggung jawabkan. Sehingga dapat menghindarkan diri dari hoax ataupun hadits palsu yang memang sengaja dibuat untuk menyesatkan, memecah umat, dan pembuat hadits palsu pun melakukannya sesuai hawa nafsunya. Fitur-fitur di situs ini lumayan mewakili keinginan pembaca yang biasanya mencari hadits manakah yang paling kuat? Atau manakah yang termasuk hadits palsu? Dengan menaruh pilihan tersebut di hasil pencariannya. Sehingga kita bisa dengan tenang berselancar mencari tau artikel artikel tentang agama yang benar tanpa harus takut jika haditsnya palsu, dan juga bisa saling mengingatkan orang yang lain kalau-kalau mereka salah menggunakan hadits atau salah ayat.

\section{KESIMPULAN}

Teknologi ada untuk memudahkan manusia dan membantu pekerjaan manusia. Dampak buruk dari kurangnya pengetahuan kita tentang teknologi dapat membuat kita terdampak berita hoax yang beredar luas. Google Custom Search dapat digunakan sebagai media awal untuk membuat perubahan dalam membantu manusia untuk mencari sesuatu yang dapat dipertanggung jawabkan hasil penelusurannya. Situs Yufid.com telah menunjukan bahwa teknologi yang ada dapat membantu kita untuk mendapatkan pengetahuan tentang agama dalam bentuk yang dapat di pertanggung jawabkan secara ilmiah, karena semua hasil pencarian yang mereka sorting memiliki catatan kaki yang cukup lengkap. Dan semua penulisnya pun juga berpendidikan agama yang benar dan tidak sesat. Namun akan lebih baik lagi jika kita bisa dan mau menuntut ilmu syar'i dan mendatangi majelis 'ilmu. Dengan Metode ini kita dapat mengetahui Dengan Penggunaan Google Custom Search, Yufid.com bisa membantu mengatasi salah satu persoalan yang lumayan berat dan beresiko, yakni membantu umat yang masih belum mengerti banyak persoalan agama yang benar apalagi tentang Al-Qur'an dan Hadits agar mendapatkan hasil pencarian yang benar dan tidak bercampur dengan website-website yang sesat yang membuat mereka melakukan kesalahan dalam beribadah. 


\section{DAFTAR PUSTAKA}

[1]Ibnu Qayyim Al-Jauzi, 2003, Al-Maudhu 'at Min Ahadits Al-Marfu'at, Darul Kutub Ilmiyah, Beirut

[2]Thahhan, Mahmud. 2017, Musthalah Al-Hadits (Dasar-Dasar Ilmu Hadits), diterjemahkan oleh Asadullah, Bahak, Ummul Qura, Jakarta.

[3]Imam Jalaluddin as-Suyuthi. 2002, Tadrib Ar-Rowi Fi Syarh Taqrib An-Nawawi, Dar Al Hadits, Mesir

[4]Adz-Dzahabi, 2019, Al-Kaba'ir (Dosa-Dosa yang Membinasakan), diterjemahkan oleh Asban bin Ali, Darus Sunnah Press, Jakarta

[5]Asy Syaikh al Muhaddits Muhammad bin Nashiruddin Al Albani, 2018, Silsilatul-Ahaadiits adh-Dhaifah wal-Maudhu'ah wa Atsaruhas-Sayyi' fil-Ummah (Silsilah Hadits Dha 'if Dan Maudhu'), diterjemahkan oleh Drs. As'ad Yasin, Gema Insani, Jakarta

[6]Ibnu Taimiyyah, 1993, Qoidah Jalilah Fii Attawasul wal Wasilah, Pustaka as-Sunnah, Jakarta

[7]Muhammad bin Ibrahim Al-Hamd, 1998, Ad-Du'a Mafhuumuhu, Ahkaamuhu, Akhtaaun, taqa 'u fiihi, Daar Ibnu Khuzaimah, Riyadh

[8]Redaksi Tempo, 2017, Kabar Sesat Di Atmosfer Kita, TEMPO, Edisi 0045, hal 25

[9]Nughroho, Septiaji Eko, 2017, Upaya Masyarakat Anti Fitnah Indonesia Mengembalikan Jatidiri Bangsa dengan Gerakan Anti Hoax, Prosiding Konferensi Nasional Peneliti Muda Psikologi Indonesia 2017, Tangerang Selatan, 23 April

[10] Banyumurti, Indriyatno, 2018, Mengenal Hoaks, Banyumurti.net, Jakarta

[11] Septanto, Henri, 2018, Pengaruh HOAX dan Ujaran Kebencian Sebuah Cyber Crime Dengan Teknologi Sederhana di Kehidupan Sosial Masyarakat, KALBIScientia, No.2, Vol.5, 157-162, http://research.kalbis.ac.id/Research/FrontEnd/Kalbiscientia/index.jsp\#content, diakses tanggal 14 November 2019

[12] Chattopadhyay, Sougata dan Mukhopadhyay, Chinmay, 2019. Integration of Google CSE with KOHA LMS: Personalised Discovery Service @ St Xavier's College Central Library, Conference: IndKoha 2019. Howrah. March

[13] Dhara, Arup, 2016. A personalised discovery service using Google custom search engine, Annals of Library and Information Studies, Vol. 63, 298-305, http://14.139.47.23/index.php/ALIS/article/view/13880/1106, diakses tanggal 15 November 2019 